\title{
The application of life cycle assessment to design
}

\author{
Gregory A. Keoleian \\ National Pollution Prevention Center, School of Natural Resources and \\ Environment, University of Michigan, Dana Building, 430 E. University, Ann Arbor, \\ MI 48109-1115, USA
}

Received 17 July 1993; revised 22 November 1993

\begin{abstract}
This paper explores the practical application of life cycle assessment (LCA) to product system development. While life cycle assessment methods have been studied and demonstrated extensively over the last two decades, their application to product design and development has not been critically addressed. Many organizational and operational factors limit the integration of the three LCA components (inventory analysis, impact assessment and improvement assessment) with product development. Design of the product system can be considered a synthesis of individual decisions and choices made by the design team, which ultimately shape the system's environmental profile. The environmental goal of life cycle design is to minimize the aggregate environmental impacts associated with the product system. Appropriate environmental information must be supplied to decision makers throughout each stage of the development process to achieve this goal. LCA can serve as a source of this information, but informational requirements can vary as the design moves from its conceptual phase, where many design choices are possible, to its detailed design and implementation. Streamlined approaches and other tools, such as design checklists, are essential. The practical use of this tool in product development also depends on the nature and complexity of the product system (e.g. new vs. established), the product development cycle (time-to-market constraints), availability of technical and financial resources, and the design approach (integrated vs. serial). These factors will influence the role and scope of LCA in product development. Effective communication and evaluation of environmental information and the integration of this information with cost, performance, cultural and legal criteria will also be critical to the success of design initiatives based on the life cycle framework. An overview of several of these design initiatives will be presented.
\end{abstract}

Keywords: life cycle assessment; product development; design

\section{Introduction}

The design of a product system can be represented logically as a series of decisions and choices made by individual design participants. These choices range from the selection of materials and manufacturing processes to choices relating to shape, form and function of the product. A design team represents a wide range of functional responsibilities including industrial design, process engineering, product development management, accounting, purchasing, marketing, human and ecosystem health, safety, and regulatory compliance. Each decision or choice made by these team members during development and implementation will shape the overall environmental profile of the product system.

Life cycle assessment (LCA) has emerged as the most comprehensive analytical tool for evaluating the environmental profile of a product. LCA refers to the techniques used in identifying, evaluating and reducing the adverse environmental effects associated with a product life cycle system ${ }^{1-5}$. A diagram of this system is shown in Figure 1. The material and energy inputs and outputs are traced from the acquisition of raw materials through manufacturing, use and product retirement to the ultimate fate of residuals released to the environment. This framework enables an analysis of the full range of environmental consequences relating to the product.

Inventory analysis, impact assessment and improvement assessment components of LCA are becoming widely recognized tools for environmental assessment and management. Applications of these tools include establishing a baseline for comparative analysis, ecolabelling and product certification, support for policy making, public education, new product design, and design improvement of existing products.

The environmental objective of product design can 

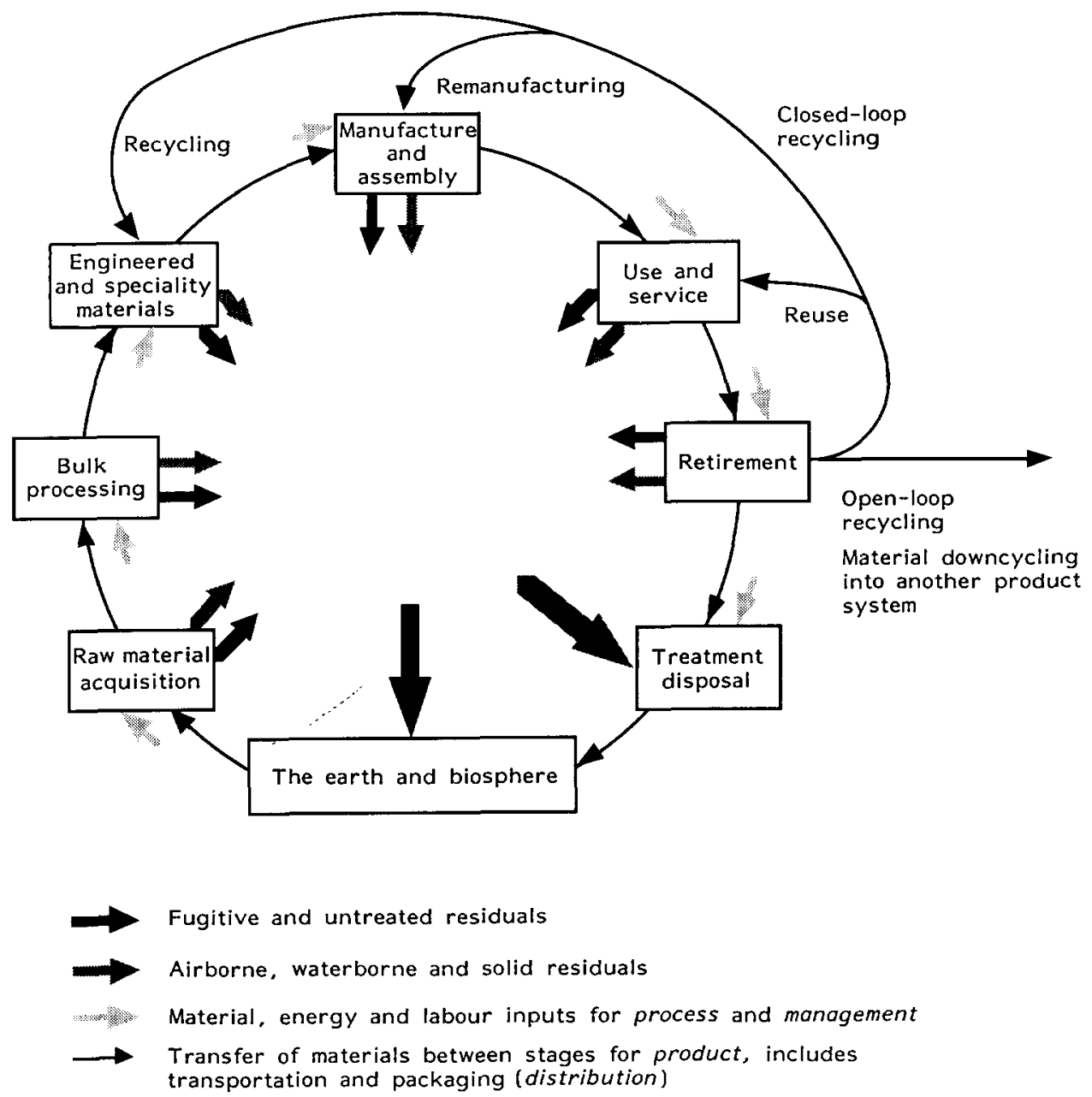

Figure 1 The product life cycle

be stated simply as a minimization of the aggregate environmental effects attributed to product development and implementation. These environmental effects can include resource depletion, energy consumption, waste generation, and adverse human and ecosystem health effects. It can be hypothesized that without a systematic tool to evaluate environmental effects, product design will be less likely to approach an optimum state of environmental quality.

This paper addresses practical issues in applying LCA techniques to product system design and development. While the discipline of LCA has advanced significantly over the last two decades, its application to design has not yet been studied in depth.

The first part of the paper focuses on fundamental limitations of the LCA methodology itself. The second addresses the potential uses of LCA in design. Both organizational and operational challenges must be overcome for successful integration of LCA and design. The third part reviews a few state-of-the-art approaches to design that are based on the life cycle framework. The distinction between LCA and design approaches, such as design for environment (DFE) and life cycle design, will be made.

\section{Limitations of life cycle assessment tools}

A description of the inventory, impact and improvement components of LCA will not be provided here but is documented in several sources ${ }^{1-5}$. The conceptual framework for LCA is well developed, but many difficulties and limitations presently restrict the practical application of LCA. Practical application of LCA to design is ultimately controlled by methodological factors relating to goal definition and scoping, data collection, data analysis and communication of results. Table 1 summarizes major issues that can be problematic in conducting an LCA.

Both cost and time constraints currently limit the practice of $\mathrm{LCA}^{6,7}$. Small companies are unlikely to be able to afford to specialize in LCA or sponsor studies externally. Even for larger firms the benefits of investment in LCA may not be immediately apparent. In some cases, potential cost savings may not be identified unless full cost accounting systems have been instituted ${ }^{8,9}$. To be most cost effective, LCA should be integrated into the existing environmental management system and information systems within a company.

Efforts to shorten the product development cycle 
Table 1 General difficulties and limitations of the LCA methodology

Goal definition and scoping

Data collection

Data evaluation

Information transfer analyse. ted.
Costs to conduct an LCA may be prohibitive to small firms; time required to conduct LCA may exceed product development constraints especially for short development cycles; temporal and spatial dimensions of a dynamic product system are difficult to address; definition of functional units for comparison of design alternatives can be problematic; allocation methods used in defining system boundaries have inherent weaknesses; complex products (e.g. automobiles) require tremendous resources to

Data availability and access can be limiting (e.g. proprietary data); data quality, including bias, accuracy, precision and completeness, are often not well addressed.

Sophisticated models and model parameters for evaluating resource depletion, and human and ecosystem health may not be available or their ability to represent the product system may be grossly inaccurate. Uncertainty analyses of the results are often not conduc-

Design decision-makers often lack knowledge about environmental effects, and aggregation and simplification techniques may distort results. Synthesis of environmental effect categories is limited because they are incommensurable.

due to time-to-market pressures can also impede the use of LCA. Shortened development cycles provide businesses with more flexibility and speed in responding to the market demands, which can be a competitive advantage. The extensive time generally required to conduct an LCA may interfere with the regular product development cycle.

Although significant progress has been made towards standardization of LCA methodology ${ }^{1-4}$, results from life cycle inventory analyses of the same product can vary significantly ${ }^{10,11}$. Order of magnitude differences are not uncommon. Discrepancies can be attributed to differences in assumptions and system boundaries. Variability among results can be attributed to rules for allocation, which are required when multiple products or processes are involved. Selection of a logical rule among mass, economic, functional unit or some other basis can be very subjective. Rules for defining system components can also be arbitrary, for example labour inputs are routinely neglected. The exclusion of labour or administrative services and other system components without testing their level of significance can distort the resource and environmental profile of the product system.
Inadequate data and information has been identified as a primary obstacle for $\mathrm{LCA}^{6}$. A recent series of interviews with 40 designers, product development managers and environmental managers indicated that the scarcity of environmental information was a major barrier to design improvement ${ }^{9}$. In the case of impact assessment, availability of models and model parameters for evaluating human and ecosystem health effects based on both toxicity and exposure may be limiting. Simplifying approaches for impact assessment, such as the 'critical volume or mass' method, have fundamental limitations ${ }^{5}$. These approaches represent only crude measures of potential health effects compared to more elaborate site-specific assessment models.

Ultimately, the characterization of the environmental effects associated with a product system will be dependent on the definition of system boundaries, quality of input data, and the sophistication and accuracy of data analysis models. Another major shortcoming of most LCA studies to date is the lack of uncertainty analysis of results.

LCA studies are extremely complex and challenging owing to the size of the product system, the size of the data requirements and the diversity of data evaluation techniques used to determine environmental effects. Synthesis of environmental effects data is inherently complicated because of the incommensurable nature of measurement units. For example, kilojoules, cancer risks and kilograms of solid waste are difficult to combine without some type of valuation model. In some cases primary information from an LCA can be directly interpreted by design participants. Alternatively, primary environmental information from LCA will be translated so that it becomes more useful to design participants. Information may be modified through aggregation, disaggregation, truncation and other simplifying procedures, which can lead to distortions in understanding the original system. These factors can all be significant in the communication and interpretation of LCA results by design decisionmakers and other users who often lack the knowledge to interpret environmental information.

\section{Integration of LCA and design}

A major challenge facing design decision-makers is assessing how their decisions, both individually and collectively, affect the overall system design. Many decisions have a major influence on the environmental profile of the system. For example, material selection in product design will affect the environmental effects associated with each stage of the life cycle, from raw materials acquisition and processing to product retirement options such as recycling. In contrast, process design decisions for product manufacturers may have less far-reaching implications on the overall system. 
Many different models can be constructed to represent design and product development ${ }^{12}$. The following elements are common to most product development approaches: needs analysis and problem statement, specification of design requirements and the specific design functions from conceptual design to detailed design. The application of LCA components to the major phases of product development will be analysed.

\section{Needs analysis}

Design projects are initiated by recognizing the need for change or uncovering opportunity for new product development. Opportunities are created from several sources, such as research and development and customer focus groups. Environmental assessments are also potential sources for initiating design projects. Environmental assessments can range from a comprehensive LCA to a 'life cycle review'-a less rigorous or semiquantitative assessment of environmental effects.

Continuous environmental improvement through design requires a basis for comparing the environmental effects of a product system. LCA is the most comprehensive tool to establish a baseline of environmental effects. Improvement is difficult to affirm without a methodology to measure and aggregate system environmental effects. In some cases, improvement can be verified without a full-scale LCA. The scope of analysis can be limited when components and/or stages of the life cycle system are static or unchanged by the development activity. These segments of the system could be excluded from the analysis.

Life cycle improvement analysis represents another important LCA tool that can be used for design. The environmental profile of an existing product system is established first by conducting life cycle inventory and/ or impact assessment. This profile is analysed to identify opportunities for design improvement. Improvement analysis, however, represents a sequential rather than an integrated approach to environmental design. Since improvement analysis is performed on an existing product system, it may be of limited use if the new design deviates significantly from the original design. Conversely, many mature products undergo incremental changes; in this case improvement analysis can be implemented more easily.

One approach to improvement analysis is to improve a new design by targeting major effects in the design of the existing system. This requires screening environmental effects. The analyst needs to link these effects with their specific sources so that new design alternatives can be formulated. This approach may be less complex when the major effects can be addressed by solutions that are localized. Solutions that result in multiple changes in the overall system could potentially create new impacts which exceed the net impacts of the original design. For this reason, process-oriented design interventions, specific to a single life cycle stage or substage, are probably easier to implement than product-oriented design interventions, which may have a greater effect on the overall system.
Although a technical design improvement may be proposed to mitigate adverse environmental effects, other factors may dominate, and improvement analysis should not be conducted to the exclusion of other design analysis procedures.

\section{Specification of requirements}

Specification of design requirements is generally considered the most critical element of design ${ }^{13}$. Requirements define the expected design outcome, and design alternatives are evaluated based on how well they meet these requirements. Adverse environmental effects of the product system can be eliminated or reduced through design specifications that focus the design solution in the direction of environmental improvement.

An LCA of an existing product system can be used to specify requirements in the design of a new product system. The environmental effects associated with an existing product can be used to establish environmental constraints for the new design. Constraints can be applied to substages, entire stages or the full life cycle based on LCA data. Tighter constraints relative to the existing product can help guide improvement. For example, if the existing system consumes $x$ units of energy per life cycle, then $0.8 x$ may be applied as a constraint on the new design. Furthermore, the $0.2 x$ reduction can be allocated to specific stages or substages within the life cycle.

Several barriers to environmental design can be hypothesized. Environmental goals are less likely to be achieved if environmental requirements are not specified explicitly. In addition to environmental requirements, the design must satisfy performance, cost, legal and aesthetic requirements of the system. The ability of the design to meet the environmental requirements will be affected by the relative weighting or importance assigned to these requirements. For example, many of the environmental effects identified by a life cycle inventory analysis may not be directly translated into costs incurred or reported by a corporation, because they are not reflected in the market system or not internalized by the corporation.

Successful design solutions will require balancing the trade-offs between multiple requirements. Conflicts between requirements can be resolved more effectively when the design decision-makers understand the interrelationships between these criteria. Furthermore, the environmental management system of a company must include environmental performance measures to monitor progress and provide necessary incentives and rewards for individuals or groups responsible for improvement. A more thorough treatment of integrating environmental requirements into design is provided in ref. 9.

\section{Evaluation of design alternatives}

The use of LCA in the evaluation of design alternatives during the conceptual, preliminary and detailed design 
stages has not been explored previously. Ideally, the life cycle environmental implications of each design choice would be available to design decision-makers. Unfortunately, the application of LCA in this phase of product development is currently limited. Real-time access to environmental data is extremely limited. In general, information databases are not yet mature enough to allow ready access to data on environmental effects for design decision-making.

LCA software tools and computerized databases (e.g. SimaPro, LCA Inventory Tool, PIA-SimaPro was developed by the Centre of Environmental Science (CML), Leiden University; LCA Inventory Tool was developed by Chalmers Industriteknik; PIA was developed by the Instituut voor Toegepaste Milieu Economie (TME) and the Bureau voor Milieu en Informatica (BMI)) are beginning to facilitate the evaluation of design alternatives. These tools can significantly shorten analysis time and offer a means to explore design alternatives through computer simulation.

In the conceptual design phase, full-scale LCA is severely restricted by the unspecified nature of the product system. A comprehensive quantitative model cannot be constructed on such a system. In this design phase, streamlined LCA techniques based on qualitative or semiquantitative information and design checklists would be more useful. Design guidelines and checklists specify criteria or rules that designers should address, such as rules specifying recyclability of packaging or product disassembly requirements.

After the design has been specified in detail, the complete set of life cycle environmental effects of the product system can be evaluated. At this stage the opportunities for design change become drastically limited. This condition is represented graphically in Figure 2. In the conceptual design phase, the design solution space is wide, whereas in detailed design, the solution space narrows. Accordingly, the practical

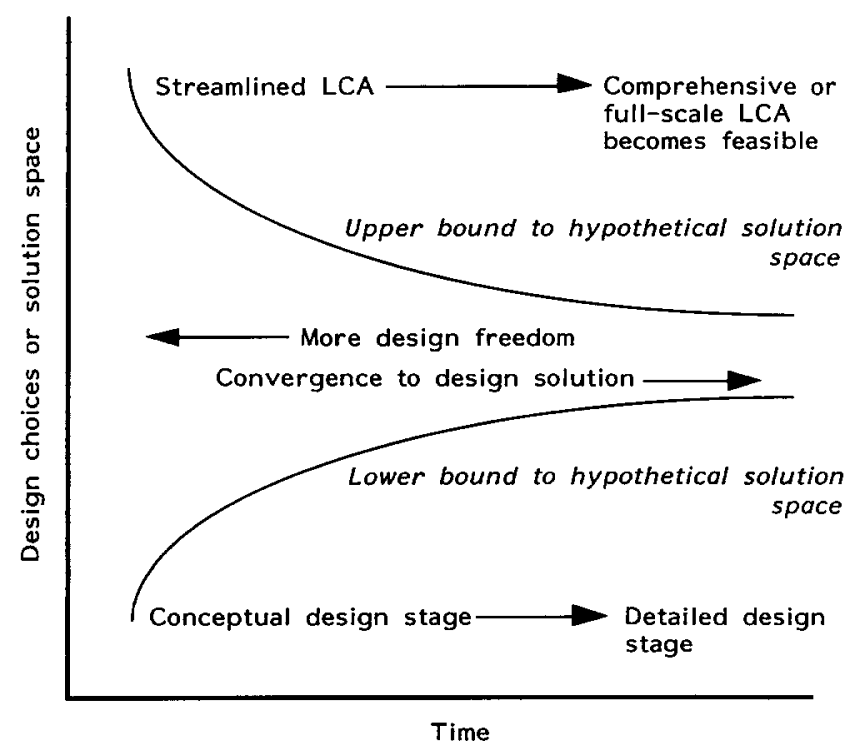

Figure 2 Design solution space as a function of time applicability of a comprehensive LCA is inversely related to the opportunity to influence the design of the product system. In addition to these limitations, many of the secondary and tertiary inventory items of a life cycle system that are often neglected in an LCA, such as facilities and equipment, are significant forces that greatly affect product development.

A comparison of LCA with financial analysis, market analysis and other product development analysis procedures may be useful in the future for understanding its application to design. For example, the issue of incommensurable factors is not unique to environmental analysis. In financial analysis, many of these measures are also incommensurable (net savings, return on investment, payback period).

The success in applying LCA to product development will also depend, in part, on the nature of the product development project. The complexity of the product system will in turn influence the complexity of the analysis accordingly. The number of material types, components, process steps and distribution segments will define the level of effort necessary to conduct the analysis. LCAs of complex products, such as automobiles, would require tremendous resources to undertake. Most studies available in the public domain have evaluated relatively simple products, often consisting of single materials ${ }^{10}$.

In practice, it is much easier to analyse a product system that is well established compared to one that is rapidly changing or transient. In the latter case, the time to conduct an assessment may approach the timescale of the development cycle, which becomes problematic. Rapidly changing product systems may require significant changes in system boundaries and changes in input data. Complex products with short development cycles (less than one year) can make current LCA capabilities insignificant.

The time lag between analysis and design of the product system, and the actual production, use and retirement of the product can be significant. In the case of automobiles, an indefinite period of time would be required at present for a comprehensive assessment: the time period for design can range from 2 to 5 years and the useful life of a vehicle averages about 10 years. Furthermore, the data available for the LCA may not even be representative of current technology let alone be useful for predicting future scenarios. The dynamic nature of the life cycle system presents a major challenge in both assessment and design.

\section{Current design initiatives}

The importance of the product life cycle in design is well recognized ${ }^{14-22}$. Several design methodologies and projects that focus on the life cycle of a product will be discussed here. Most published life cycle inventory analyses have compared product alternatives ${ }^{11}$, and very few comprehensive analyses have been used for internal design decision-making. The product ecology project $^{23}$ represents one example where life cycle 
inventory and a valuation procedure are used to support product development. For this project, the EPS system (environmental priority strategies in product design) is used to evaluate design alternatives in terms of environmental load units, which is a single metric for evaluating environmental impact. The inventory is conducted using the LCA Inventory Tool and the valuation is based on a willingness-to-pay model, which accounts for biodiversity, human health, production, resources and aesthetic values. This system enables the designer to easily compare alternatives, but the reliability of the outcome will be heavily dependent on the valuation procedure.

Two commonly used terms that address environmental objectives through design are design for environment (DFE, also referred to as design for the environment) and life cycle design. The DFE method, developed by Allenby ${ }^{15,16}$, utilizes a semiquantitative matrix approach for evaluating life cycle environmental impacts. A graphical scoring system was created to weight environmental effects based on available quantitative information for each life cycle stage. In addition to an environmental matrix and toxicology/ exposure matrix, manufacturing and social/political matrices are used to address technical and broader non-technical aspects of design alternatives.

The life cycle design approach, developed for the US Environmental Protection Agency ${ }^{9,19}$, emphasizes the specification of environmental, performance, cost, cultural and legal requirements for the life cycle system. A multicriteria matrix is used to identify and resolve conflicts between requirements. Elements of the matrix are defined by life cycle stages and product system components (product, process, distribution, management). This matrix was developed to facilitate involvement of a cross-functional design team, including industrial designers, process engineers and business managers. It is anticipated that full participation and cooperation of the design team will enhance a corporation's effectiveness in achieving reduced environmental burden while optimizing other critical design requirements. Demonstration projects are currently being conducted with AT\&T and Allied Signal Corporation.

Additional design methods and projects, including 'eco-design'24, are described in ref. 25 . In the USA, $A T \& T^{18}$ and $X \operatorname{Xrox}^{26}$ have initiated major programmes in DFE and life cycle design. Research is underway to develop $\mathrm{CAD} / \mathrm{CAE}$ tools to support the integration of environmental objectives into engineering design ${ }^{27}$.

Regulations and ecolabelling can also be effective in focusing product developers to address life cycle environmental consequences of their products ${ }^{28}$. Corporations are responsible for compiling and reporting environmental information on their products and processes under the authority of government regulations. In the USA, the life cycle framework is most rigorously mandated under the Toxic Substances Control Act (TSCA) for new chemical product development. TSCA requires environmental testing of chemical substances and mixtures if 'the manufacture, distribution in commerce, processing, use, or disposal of a chemical substance or mixture, or that any combination of such activities, may present an unreasonable risk of injury to health or the environment'. The 'takeback' legislation proposed in Germany also extends the system boundaries for which manufacturers are legally responsible. This will force designers to address 'end of life' issues more carefully. Most ecolabelling programmes, particularly in Europe, have used the life cycle framework to establish labelling criteria or standards $^{29}$, which also can have a significant influence on product development.

\section{Conclusions}

Analysis represents only one function in design, which also includes creativity and the synthesis of concepts and resources in formulating the final product. Some of the limitations in LCA are related to potential conflicts between these elements of design. The integration of LCA into design must address the relationships between physical system (defined by material and energy flows) and the design decisionmaking process (represented by the flow of information). The temporal and spatial relationships between the physical flows and the information flows must be considered.

The lack of knowledge and expertise about environmental effects on the part of design participants is a major limitation to achieving environmental objectives. Improvement in the availability and quality of environmental information provided to decision-makers in design and management is necessary to reduce the environmental impacts associated with a product system. Designers require the same access to environmental data as they have to performance and cost data.

LCA provides an organizing tool for developing environmental information about a product system. LCA techniques range from streamlined assessments or life cycle reviews to full-scale comprehensive assessments. The appropriate technique will depend on the specific design application, as indicated in Table 2. But until life cycle analysis databases are more mature, designers must rely on streamlined LCAs, design guidelines and checklists, and other simplified approaches. For this reason, many corporate initiatives have focused more on 'design for environment' and 'life cycle design' approaches rather than comprehensive LCA techniques.

The current limitations of the LCA methodology, summarized in Table 1 , should not detract from the contributions that LCA brings to the field of environmental design. Design is a synthesis of various constituent interests both internal and external to the manufacturing firm. The life cycle system is a useful framework for balancing these diverse interests. LCA is still a relatively new tool that will require significant changes to be successfully implemented. Yet use of this tool and the life cycle framework represents 
Table 2 Summary of applications of LCA to product system design

Needs analysis

Project definition: use streamlined LCA for initial project screening; use improvement analysis to identify opportunities for reducing environmental burdens (e.g. target major impacts).

Baseline environmental profile: conduct LCA on the existing product system to establish a baseline for comparative analysis.

Specification of requirements

Use LCA information for the existing product system to guide improvement of new designs.

Evaluation of design alternatives

Conceptual design: use streamlined LCA techniques to formulate and evaluate design concepts; at this stage the system is not sufficiently defined to conduct a full-scale LCA.

Detailed design: full-scale LCA is possible but at this stage the design is fixed and opportunities for improvement are limited.

an important shift towards a systems approach in environmental management.

\section{Acknowledgements}

Funding was provided to the author by the United States Environmental Protection Agency, through a Cooperative Research Project (CR-817570) between the University of Michigan and the Risk Reduction Engineering Laboratory, Cincinnati, OH. Views expressed herein do not necessarily reflect those of the Agency.

\section{References}

1 US Environmental Protection Agency, Office of Research and Development, Risk Reduction Engineering Laboratory, 'Product Life Cycle Assessment: Inventory Guidelines and Principles', EPA/600/R-92/245, (prepared by Battelle and Franklin Associate), US EPA, Cincinnati, OH, 1993

2 Fava, J.S., Denison, R., Jones, B., Curran, M.A., Vigon, B., Selke, S. and Barnum, J. (Eds) 'A Technical Framework for Life-cycle Assessments', Society of Environmental Toxicology and Chemistry, Washington, DC, 1991

3 Consoli, F., Allen, D., Boustead, I., de Oude, N., Fava, J., Franklin, W., Quay, B., Parrish, R., Perriman, R., Postlethwaite, D., Seguin, J. and Vigon, B. (Eds) 'Guidelines for Life-Cycle Assessment: A "Code of Practice", Society of Environmental Toxicology and Chemistry, Washington, DC, 1993

4 Heijungs, R., Guinée, J.G., Huppes, G., Lankreijer, R.M., Udo de Haes, H.A., Wegener Sleeswijk, A., Ansems, A.M.M., Eggels, P.G., van Duin, R. and De Goede, H.P. 'Environmental Life Cycle Assessment of Products-Guide and Backgrounds', Centre of Environmental Science, Leiden University, 1992

5 Guinée, J.B., Udo de Haes, H.A. and Huppes, G. J. Cleaner Prod. 1993 1, 3

6 Sullivan, M.S. and Ehrenfeld, J.R. Total Qual. Environ. Manage. 1992/93, (Winter), 1143

7 White, A.L. and Shapiro, K. Environ. Sci. Technol. 1993, 27 (6), 1016

8 US Environmental Protection Agency, Office of Pollution Prevention and Toxics, 'Total Cost Assessment: Accelerating Industrial Pollution Prevention through Innovative Project Financial Analysis', (prepared by A.L. White, B. Becker and J. Goldstein, Tellus Institute, Boston, MA), US EPA, Washington, DC, 1992

9 US Environmental Protection Agency, Office of Research and Development, 'Life Cycle Design Guidance Manual: Environmental Requirements and The Product System', EPA/600/R-92/226, (prepared by G.A. Keoleian and D.Menerey, National Pollution Prevention Center, School of Natural Resources and Environment, University of Michigan), US EPA, Cincinnati, OH, 1993

10 Svensson, G. Proceedings of First NOH European Conference Design for the Environment, 21-23 September 1992, Nunspeet, The Netherlands, Novem, Utrecht, pp. 1-8

11 Curran, M.A. Environ. Sci. Technol. 1993, 27 (3), 430

12 Jones, J.C. 'Managing Design Methods', Wiley, New York, 1980

13 Gause, D.G. and Weinberg, G.M. 'Requirements: Quality Before Design', Dorset House, NewYork, 1989

14 Asimov, M. 'Introduction to Design', Prentice-Hall, Englewood Cliffs, NJ, 1962

15 Allenby, B.R. Semiconductor Safety Assoc. J. 1991, (September), 5

16 Allenby, B.R. and Fullerton, A. Pollut. Prev. Rev. 1991-92, (Winter), 51

17 Alting, L. Proceedings, First International Congress on Environmentally Conscious Engineering Design, 4-5 May 1992, Boston, MA, Management Roundtable, Boston

18 Glantschnig, W.J. Proceedings of 1993 IEEE International Symposium on Electronics and the Environment, Arlington, VA, IEEE, Piscataway, NJ, 1993, pp. 74-78

19 Keoleian, G.A., Menerey, D. and Curran, M.A. Pollut. Prev. Rev. 1993, 3 (Summer), 293

20 Stahel, W.R. Paper presented at Design as Strategy-IDSA National Conference, 8-11 August 1990, Santa Barbara, CA

21 Van Weenen, J.C. PhD Dissertation, Delft Technical University, The Netherlands, 1990

22 Wenzel, H. Proceedings of First NOH European Conference Design for the Environment, 21-23 September 1992, Nunspeet, The Netherlands, Novem, Utrecht, pp. 1-12

23 'Product Ecology Project Report', Information Group, Federation of Swedish Industries, 1993

24 Van Weenen, J.C., Bakker, C.A. and de Keijser, I.V. 'EcoDesign: An Exploration of the Environment in Product Design', Dutch Ministry of Economic Affairs, 1992

25 Proceedings of First NOH European Conference Design for the Environment, 21-23 September 1992, Nunspeet, The Netherlands, Novem, Utrecht

26 Azar, J. EPA J. 1993, 19 (3), 14

27 Navinchandra, D. Proceedings, International Conference on Engineering Design, 17-19 August 1993, De Hague, The Netherlands, Heurista, The Hague, pp. $780-787$

28 US Congress, Office of Technology Assessment, 'Green Products by Design: Choices for a Cleaner Environment', OTA-E-541, 1992

29 Hirsbak, S., Nielsen, B.B. and Lindhqvist, T. 'Eco-Products: Proposal for a European Community Environmental Label', Danish Tehnnol. Institute, 1990 